\title{
Dimensões sociais da resiliência a desastres
}

\author{
Victor Marchezini \\ Centro Nacional de Monitoramento e Alerta de Desastres Naturais - São José \\ dos Campos - São Paulo - Brasil \\ Henrique Almeida Forini \\ Universidade Federal de São Carlos - São Paulo - Brasil
}

\section{Resumo}

Os estudos sociais sobre os desastres ainda são um tema de pouca pesquisa científica no Brasil, em particular àqueles que se referem aos processos de reconstrução e recuperação frente a desastres. Recentemente, esse debate tem sido impulsionado pelas ciências naturais e engenharias, que compreendem o desastre como um evento/acontecimento, ao qual cabe responder com estratégias de resiliência, isto é, de fazer frente ao evento adverso. Surgido no campo das ciências biológicas e engenharias, o termo resiliência tem sido aplicado às sociedades humanas. Entretanto, a participação das ciências sociais nesse debate ainda é incipiente. O objetivo deste artigo é discutir o conceito de resiliência a desastres, sob a perspectiva da Sociologia dos Desastres. Essa reflexão é feita à luz da revisão bibliográfica, da pesquisa documental e das pesquisas de campo, de base qualitativa, realizadas nos desastres em Ilhota/SC (2008) e São Luiz do Paraitinga/SP (2010). A partir desses elementos de pesquisa de campo, apresentam-se alguns caminhos metodológicos e teóricos para a compreensão do conceito de resiliência no âmbito da Sociologia dos Desastres. Por fim, recomendam-se alguns futuros percursos de pesquisa no tema.

Palavras-chave: Recuperação em desastres. Vulnerabilidade. Resiliência.

\section{Social dimensions of disaster resilience}

\begin{abstract}
There are few disaster studies conducted by social scientists in Brazil, in particular research related to the disaster recovery process. The debate about disaster recovery has been led by the natural and hard sciences, which have used it to frame disaster as an event that requires coping mechanisms and resilience strategies in order to bounce back. The term 'resilience' emerged in the biological and hard sciences and has been applied to human societies. Although the participation of social scientists in this debate is increasing, it is still rare to encounter sociological studies about resilience to disasters. The aim of this article is to discuss the concept of disaster resilience in light of the sociology of disaster. Based on bibliographic reviews, desk research and field research activities in the affected towns of Ilhota/Santa Catarina State (2008) and São Luiz do Paraitinga/São Paulo State (2010), the
\end{abstract}


research discusses theoretical and methodological pathways to comprehend the social dimensions of disaster resilience.

Keywords: Disaster recovery. Vulnerability. Resilience.

\section{Dimensiones sociales de la resiliencia a los desastres}

\section{Resumen}

Brasil cuenta con un número muy limitados estudios relacionados con ciencias sociales y desastres, particularmente aquellos enfocados en las etapas de reconstrucción y recuperación. Existe un debate que ha sido conducido principalmente por las ciencias naturales e ingenierías, las cuales definen desastre como un evento o acontecimiento que puede ser respondido mediante estrategias de resiliencia. Cuya definición surge dentro las ciencias biológicas e de ingeniería y que últimamente también ha sido adoptado en el campo de los desastres para referirse a las sociedades humanas. Sin embargo, la participación de los científicos de las áreas sociales es aún una discusión muy reciente. Por lo tanto, para este trabajo se ha realizado una revisión bibliográfica, investigación documental e investigaciones in situ en dos áreas de estudio: Ilhota, en el Estado de Santa Catarina y São Luiz do Paraitinga, en el Estado de São Paulo. El cual tiene como objetivo generar una discusión sobre el concepto de resiliencia desde el punto de vista de la Sociología de los Desastres y en donde se proponen sugerencias para futuras investigaciones.

Palabras clave: Recuperación en desastres. Vulnerabilidad. Resiliencia.

\section{Introdução}

Palavras, números e imagens são alguns dos elementos utilizados para produzir uma ideia de realidade, a qual, no entendimento de Pierre Bourdieu (2004), é sempre resultado de uma luta simbólica pela imposição da visão oficial, luta esta que é travada em um campo de poder, formado pelas relações entre agentes sociais com diferentes graus e formas de capital econômico, simbólico, cultural, político, científico etc. Esses campos perpassam as dimensões da vida social, em espaços sociais presenciais e virtuais, e se aplicam aos desastres.

A palavra desastre deriva do latim dis (mau, contrário, inadequado) + aster (astro) e representaria, se fiel às suas raízes etimológicas, uma desgraça ocasionada por influência danosa dos astros. É perceptível o afastamento dessa palavra ao seu conteúdo original, porque palavras também são objeto de luta simbólica. Desastre é objeto de disputas em diversos campos de poder, tais como o midiático, político, jurídico, científico. Um dos reflexos dessas lutas simbólicas orbita em torno da utilização ou não do adjetivo "natural" junto à palavra desastre. No campo científico, por exemplo, há um longo debate sobre o assunto (O'KEEFE et al., 1976; MASKREY, 1993; MARCHEZINI, 2009; VALENCIO, 2012).

Se compreendido como evento/acontecimento é comum que a ideia de desastre seja equiparada à ocorrência do fenômeno natural como, por exemplo, às chuvas que contribuem para encher o rio que, caso assoreado, pode extravasar, causando, assim, uma inundação. Se as margens do rio forem ocupadas por moradias e/ou estabelecimentos comerciais, é provável que ocorram perdas nessa inundação. Se essas perdas excederem a capacidade local de fazer frente à situação, o resultado será o desastre. As chuvas são um fenômeno natural, enquanto o desastre é socioambiental. 
Para além dessa adjetivação ou não do conceito de desastre, cabe destacar as abordagens que o consideram como um evento/acontecimento ou como um processo. Essas abordagens terão implicações em relação aos modos como os agentes sociais atribuem o "fim" ou a "continuidade" do desastre. Se compreendido como "evento/acontecimento", a temporalidade do desastre será balizada pela duração do fenômeno natural (chuvas, por exemplo), e não à vivência social das perdas. Nesse caso, a dinâmica desigual do campo de poder lhe decreta o fim, o "pósdesastre". Já a abordagem processual busca analisar as causas de fundo da vulnerabilidade - desigualdade de renda, de poder, ideologias etc. - e as pressões dinâmicas - preço das commodities no mercado internacional, rápida urbanização etc. - que contribuem para a criação de condições inseguras de vida como, por exemplo, residir em moradias frágeis, construídas sobre taludes de corte e aterro e com lançamento de águas servidas (BLAIKIE et al, 2005; WISNER et al, 2012). Além de compreender os fatores sociais de produção social do risco de desastre (VALENCIO et al, 2004; ACOSTA, 2005), a abordagem processual também pode ser aplicada em análises longitudinais acerca das formas de continuidade do desastre (VALENCIO, 2012; MARCHEZINI, 2014a; 2014b), identificando, por exemplo, dinâmicas de abandono social no decorrer do processo de reconstrução e recuperação (VALENCIO, SIENA, MARCHEZINI, 2011; MARCHEZINI, 2014a; 2014b; 2014C).

Esse campo de pesquisa ainda está em consolidação no Brasil, sobretudo no âmbito das Ciências Sociais (MARCHEZINI, 2018). Os estudos voltados à análise dos processos de recuperação e reconstrução ainda são escassos no Brasil (VALENCIO, SIENA, MARCHEZINI, 2011; VALENCIO, 2012; SIENA, 2012; MARCHEZINI, 2014a; SARTORI, 2014, SANTOS, 2015; SANTOS, 2016). É nesse contexto da recuperação e reconstrução em desastres que emerge um novo conceito no campo de poder em torno do desastre: o conceito de resiliência. O objetivo deste artigo é discutir o conceito de resiliência a desastres, sob a perspectiva da Sociologia dos Desastres. Para tanto, na primeira seção deste artigo, discute-se a emergência do conceito de resiliência e sua aplicação no campo da ciência e da gestão em risco de desastres. Em seguida, apresentam-se alguns resultados de pesquisas de campo realizadas nos desastres em Ilhota/SC (2008) e São Luiz do Paraitinga/SP (2010). A partir desses elementos de pesquisa de campo, apresentam-se alguns caminhos metodológicos e teóricos para a compreensão do conceito de resiliência no âmbito da Sociologia dos Desastres. Por fim, recomendam-se alguns futuros percursos de pesquisa no tema.

\section{0 conceito de resiliência no campo de desastres}

O conceito de resiliência foi introduzido nas ciências da saúde há cerca de quatro décadas e, desde então, sofreu muitas transformações, sendo utilizado por diferentes áreas científicas, como ecologia, geografia, desenvolvimento social, psicologia, saúde e afins (SOUZA, 2011). Inicialmente, o conceito era abordado como uma característica individual. Posteriormente passa a ser abordado como um processo que se desenvolve no domínio das interações humanas diante de adversidades, tendo como resultado a recuperação e superação. Ao se apreender a resiliência como um processo, pressupõe-se que existam fatores e mecanismos que contribuam - facilitando ou dificultando - seu desenvolvimento. Esses fatores são os de risco e proteção (SOUZA, 2011). 
Os fatores de risco são situações ou eventos estressores que predispõem as pessoas ou comunidades às desestruturações e crises. Entretanto, ao mesmo tempo, as coloca em condições de enfrentamento e resposta às atribulações. São ocasiões em que a resiliência se torna necessária e, assim, pode-se desenvolver (SOUZA, 2011). No que diz respeito aos fatores de proteção, Souza (2011) aponta que existem potenciais auxiliadores do enfrentamento desses desafios, que se constituem em características individuais, relações de vínculo e circunstâncias do próprio contexto que amparam a resiliência, como, por exemplo, a existência de políticas públicas de assistência social e recuperação socioeconômica de áreas atingidas em desastres.

Brandão, Mahfoud e Gianordoli-Nascimento (2011) afirmam que entre as décadas de 1970 e 1980, diversas pesquisas, conduzidas sobretudo por americanos e ingleses, demonstravam interesse no fenômeno dos indivíduos que apresentavam estabilidade, mesmo depois de expostos a situações adversas, como aquelas que causam estresse. Inicialmente esse tipo de indivíduo - hoje classificado como "resiliente" - foi chamado de invulnerável. Para além do foco no indivíduo, a utilização do conceito de resiliência tem se desdobrado para se referir a escalas espaciais diversas, como cidades, regiões, estados.

Neste sentido, as pesquisas acerca de cidades e comunidades resilientes demonstram uma tendência a interpretar o conceito de resiliência no âmbito das discussões sobre desenvolvimento socioeconômico sustentável (ONU-HABITAT, 2015; 2016; UNISDR, 2012; REBOTIER, PELÁZEZ, PIGEON, 2013). A aplicação do referencial da resiliência aos sistemas socioambientais urbanos busca considerar os constantes contextos de incerteza, na medida em que devem ser flexíveis para operar ajustamentos e assim tornarem-se capazes de capitalizar as oportunidades. Ou seja, demonstrar flexibilidade para conviver com o inesperado e se adaptar (GONÇALVES, 2016).

No âmbito propriamente da gestão de risco de desastres, a ONU (2012) tem desenvolvido orientações sobre o tema, como o guia voltado a gestores públicos, intitulado Como construir cidades mais resilientes. O referido guia caracteriza uma cidade resiliente como um local onde desastres são minimizados porque sua população vive em residências e comunidades com serviços e infraestrutura organizados e que obedecem a padrões de segurança; sem ocupações irregulares construídas em planícies de inundações ou em encostas íngremes por falta de outras terras disponíveis; que possua um governo local competente, inclusivo e transparente, que se preocupa com a urbanização sustentável, ao passo que investe os recursos necessários ao desenvolvimento de capacidades para gestão e organização municipal antes, durante e após uma ameaça natural ou desastre (ONU, 2012). Desse modo, em uma cidade resiliente as autoridades locais e a população compreendem os riscos que enfrentam e desenvolvem processos de informação local e compartilhada com base nos danos causados em desastres e riscos, levando em conta a situação de vulnerabilidade social e exposição dos grupos, ao passo que busca responder e implantar estratégias imediatas de reconstrução, restabelecendo rapidamente os serviços básicos para retomar suas atividades sociais, econômicas e institucionais após um evento adverso (UNISDR, 2012).

Ao realizar uma revisão de literatura sobre o conceito de resiliência no âmbito da ciência dos riscos e desastres, Manyena (2006) aponta algumas tendências principais que podem subsidiar as análises das pesquisas de campo nos desastres de 
Ilhota/SC e São Luiz do Paraitinga/SP. Para Manyena (2006), o ponto central consiste em apreender quais objetos estamos conferindo resiliência, posto que indivíduos, comunidades e nações possuem diferentes graus de resiliência, e podem ser definidos em termos de seus valores essenciais de sobrevivência - vida, meios de subsistência, cultura etc. Buscar-se-á contribuir para este debate a partir dos estudos de caso em dois desastres ocorridos nos municípios supracitados, compreendendoos como laboratórios sociológicos.

\section{Os desastres como laboratórios sociológicos sobre a resiliência}

Desastres podem ser considerados como laboratórios sociológicos, pois permitem aos cientistas aprimorarem a análise e compreensão das percepções, representações e práticas dos atores sociais e/ou instituições durante contextos de vivência de uma crise social coletiva. No âmbito deste artigo, discutir-se-ão alguns resultados de pesquisas de campo nos desastres de Ilhota/SC (2008) e São Luiz do Paraitinga/SP (2010).

O município de Ilhota foi criado em 1958 e está localizado na microrregião Itajaí, ao leste do Estado de Santa Catarina, na região do Vale do Itajaí. Apresenta extensas áreas de várzeas e planícies sedimentares, entremeadas de morros, altitudes de seis a 819 metros acima do nível do mar. Município com cerca de 12 mil habitantes, Ilhota tem como principais atividades econômicas a indústria de confecções, de beneficiamento de açúcar, de cultivo de arroz irrigado e de bananicultura. A crescente instalação de fábricas de biquínis e lingeries, iniciada na década de 1980, deu à cidade uma nova perspectiva para a economia local. Inúmeras lojas do setor instalaram-se nas margens da rodovia Jorge Lacerda, na planície de inundação do rio Itajaí-Açu (GOVERNO DO ESTADO DE SANTA CATARINA, 2009). Esse conjunto de atividades econômicas sofreu impactos diretos e indiretos em decorrência das inundações e deslizamentos ocorridos em novembro de 2008 e dos efeitos acarretados ao longo do tempo como, por exemplo, a interrupção do escoamento de produtos em razão da destruição/danificação de rodovias, as mortes ou condições de desabrigo por parte de empresários e trabalhadores. O formulário de Avaliação de Danos (AVADAN), preenchido no dia vinte e quatro de novembro de 2008, aponta que 980 residências populares foram danificadas e 85 destruídas. No tocante aos danos humanos, dados da Defesa Civil de Santa Catarina apontam para a ocorrência de 135 mortes num conjunto de 77 municípios que decretaram situação de emergência ou estado de calamidade pública. Em Ilhota, ocorreram 47 mortes, quase $35 \%$ do total. Os desalojados computavam 3.500 pessoas e os desabrigados 1.300 , isto é, 4.800 pessoas desterritorializadas de suas moradias ( $41,55 \%$ das 11.552 pessoas contabilizadas pelo IBGE em 2007).

O outro caso de estudo também é um município de pequeno porte, com cerca de 10 mil habitantes. Situado no estado de São Paulo, na região conhecida como Vale do Paraíba, o município de São Luiz do Paraitinga tem o turismo e o setor de serviços a ele relacionados - como pousadas urbanas e rurais, hotéis, restaurantes - como suas principais atividades econômicas. O principal evento turístico é o carnaval ocorrido nas ruas do Centro Histórico, que se situa na planície de inundação do rio Paraitinga. Em janeiro de 2010, as águas do rio Paraitinga ficaram doze metros acima do seu nível normal, atingindo $80 \%$ da área urbana. Dos 426 imóveis tombados pelo Conselho de 
Defesa do Patrimônio Histórico, Arqueológico, Artístico e Turístico do Estado de São Paulo (CONDEPHAAT), 18 foram arruinados e 65 sofreram algum tipo de agravo (PREFEITURA MUNICIPAL DE SÃO LUIZ DO PARAITINGA, 2010b). Duas igrejas, uma escola municipal, documentos públicos (da prefeitura, dos cartórios e do fórum) foram destruídos e a economia municipal ficou paralisada por quase um mês, com cerca de 225 edificações comerciais danificadas (PREFEITURA MUNICIPAL DE SÃO LUIZ DO PARAITINGA, 2010a). Foram cerca de 80 residências destruídas e 146 danificadas, com mais de 5.145 pessoas desalojadas e desabrigadas, ou seja, $49,48 \%$ da população total.

As pesquisas de campo realizadas nesses dois municípios fizeram uso da observação direta, com uso de diário de campo, da coleta de relatos orais (QUEIROZ, 1991) com a realização de entrevistas balizadas por um roteiro semi-estruturado junto a famílias/grupos domésticos atingidos e gestores públicos; e da foto-documentação (MARTINS, 2008) que auxiliou na compreensão das práticas sociais de recuperação/resiliência por parte das famílias/grupos sociais atingidos.

As visitas de campo em Ilhota/SC foram realizadas em dezembro de 2008 e em julho de 2011. Em dezembro de 2008 foram analisados dois abrigos temporários, a fim de compreender as práticas no interior do abrigo e as formas de apropriação e domínio dos espaços, os papéis e as rotinas. A visita de campo em julho de 2011 teve como objetivo analisar as dimensões objetivas e simbólicas dos grupos sociais no decorrer do processo de reconstrução e recuperação.

As visitas de campo em São Luiz do Paraitinga/SP foram realizadas em novembro de 2010 e março de 2013 e tiveram como objetivo analisar os discursos e as práticas dos agentes sociais no decorrer do processo de reconstrução e recuperação. A seguir compartilhar-se-ão alguns resultados dessas pesquisas. $O$ objetivo não é realizar uma análise comparativa, mas sim extrair elementos sociológicos relevantes para compreensão do conceito de resiliência a desastres. Esse conceito será compreendido em sua relação com três categorias fundamentais do mundo social que se entrelaçam: a família/grupo doméstico, a casa e o trabalho. As relações entre esses três elementos e as estratégias de resiliência podem ser balizadores dos modelos de re-desenvolvimento em áreas atingidas por desastres.

\subsection{A família/grupo doméstico e a casa como elementos de resiliência}

Família ou grupo doméstico é uma ordem moral com a qual os indivíduos ordenam e dão sentido, isto é, uma "referência simbólica fundamental que permite pensar, organizar e dar sentido ao mundo social, dentro e fora do âmbito familiar", uma forma de identidade social que "estrutura sua explicação do mundo" (SARTI, 2007, p.9-53). Por meio da noção de família perfazem-se códigos de obrigações que possibilitam negociar sentidos de atuação no mundo, dentro e fora do âmbito familiar, uma vez que se enredam obrigações morais entre seus membros. A inclusão nessa rede não se delimita pela vinculação a um grupo genealógico, mas há uma extensão vertical do parentesco que abarca aqueles com os quais se convive ou conviveu e em quem se pode confiar.

A casa é o território mínimo que serve como elemento de construção social da realidade pela família, é uma extensão da pessoa, um valor através do qual ela demonstra sua respeitabilidade (SARTI, 2007). A casa tem historicamente permitido 
"uma variedade de imagens e significados, seja ela entendida como uma construção específica que serve de abrigo, seja como uma imagem de um espaço simbólico de pertencimento social, de intimidade e de segurança" (HIGUCHI, 2003, p.50).

A casa pode ser conceituada como "unidade do abrigo, do descanso e do trabalho; é uma referência de todos (...) demarca a territorialidade segura" (TIDAFI, 2006, p.17), é um dos locais que permitem, mesmo que de forma precária, a execução de diversos fazeres como dormir, comer, trabalhar, descansar, banhar-se. Ter um local onde as pessoas se reúnam para fazer suas refeições é identificado como uma das mais antigas explicações para a origem da casa (GRESSLER, 2007).

Em A poética do espaço, Bachelard (1993) se questiona se seria possível isolar uma essência íntima e concreta a partir da qual justificaríamos o valor singular das nossas imagens de intimidade protegida. Para o autor, todo espaço habitado traz consigo a essência da noção de casa, sendo que a imaginação trabalha nesse sentido ao "construir 'paredes' com sombras impalpáveis para reconfortar-se com ilusões de proteção" (BACHELARD, 1993, p.25). O ser abrigado sensibilizaria os limites do seu abrigo, vivendo a casa em sua realidade e em sua virtualidade, por meio do pensamento e dos sonhos: a "casa abriga o devaneio, a casa protege o sonhador, a casa permite sonhar em paz" (BACHELARD, 1993, p.26).

Frehse et al. (1996, p.91) afirmam, a partir de um estudo sobre o imaginário onírico da metrópole paulista, que a casa "aparece em quase todos os sonhos como o lugar da segurança, do conhecido, da rotina e do aconchego", mas em quase todos os sonhos coletados está implícito, segundo Martins (1996, p.25), "um conceito de estranho e de um estranho que representa perigo e ameaça para o sonhador". 0 lugar público aparece como cenário de medo, é sempre "um lugar em que se está fugindo, não é um lugar que se permanece” (MARTINS, 1996, p.26), isto é, expressase em oposição à casa da família. É marcado pela presença de pessoas anônimas e abstratas, por uma "identidade difusa [que] não é constituída por relações concretas em que se sabe quem é o outro" (MARTINS, 1996, p.27). Enquanto o mundo da casa seria o mundo da confiança, o mundo público, tal como um abrigo temporário, seria o da desconfiança.

A perda da casa implica aos desabrigados a invasão da intimidade protegida. Se a casa é um elemento de integração para os pensamentos, as lembranças e os sonhos do homem, em que o passado, o presente e o futuro lhe dão diferentes dinamismos, procurando afastar as contingências e multiplicar a continuidade (BACHELARD, 1993), a perda do exercício cotidiano de refazimento implica a fragilização do corpo de imagens que confere à família razões e ilusões de estabilidade em sua territorialidade.

O que mantém a casa ativa e seu passado e futuro mais próximos é a atividade doméstica, que se reafirma cotidianamente. Esta constrói a casa e a conserva viva, pois a casa é reconstruída do interior, ela é nova pelo interior (BACHELARD, 1993). A partir da atividade doméstica, aos objetos são conferidos determinados sentidos, fazendo com que assumam seus lugares numa comunhão de ordem, ao terem seus vínculos delineados pelos cuidados domésticos que reconstróem o mundo da casa a partir dos objetos: "fazer tudo, refazer tudo, dar a cada objeto um 'gesto suplementar' (...) são outros tantos benefícios que nos presta a imaginação ao fazernos sentir o crescimento interno da casa" (BACHELARD, 1993, p.82). 
Bachelard (1993) considera que não somente se constrói uma casa para se viver nela, mas vive-se para construí-la e formá-la continuamente. Reportando-se à Michelet (1858), Bachelard (1993, p.113) acredita que a casa é “construída pelo corpo, para o corpo, assumindo sua forma pelo interior, como uma concha (...) A casa é a própria pessoa, sua forma e seu esforço mais imediato". Nesse sentido, Sarti (2007, p.129) afirma que a "importância da ordem e da limpeza diz respeito não apenas à casa, mas também ao corpo", razão pela qual um dos valores manipulados "para definir o mendigo, [constitui-se como] aquele que é relaxado, porco, desleixado, como o que anda de qualquer jeito, que deixa a casa de qualquer jeito". Assim, uma pessoa desleixada corresponde a uma casa desleixada.

Casa e família, como categorias fundamentais da construção da identidade no mundo social, são colocadas à prova em contextos de desastre e, em razão disso, podem ser associadas ao conceito de resiliência, isto é, de fazer frente a situações de adversidade. Compreender essas situações de adversidade sob o ponto de vista daqueles que estão na linha de frente dos desastres, como os grupos domésticos/famílias que perderam suas moradias, é essencial para análise das condições sociais desiguais de tentar ser resiliente ou não. Nesse contexto, torna-se importante pensar nas estratégias de resiliência nos abrigos temporários.

Em Ilhota, no abrigo organizado no colégio Marcos Konder, as famílias não puderam ficar cada uma em uma sala de aula, mas tiveram que dividi-la com outras, sendo que a divisão foi feita pelas famílias e não pelos coordenadores do abrigo. Em média, havia dez pessoas por quarto. No interior das salas de aula, lençóis, carteiras, cobertores constituíam-se como os artefatos a partir dos quais cada família criava fronteiras para a definição de seu território mínimo, uma tentativa de privacidade dentro da sala de aula. Pedaços de barbantes esticados serviam de suporte para prendedores que sustentavam lençóis e toalhas, recursos utilizados pelas famílias para produzir divisórias e fronteiras no interior das próprias salas, funcionando para demarcação visual a fim de controlar a possibilidade de o outro lhe ver, mas não de ouvir, de sentir cheiros. Eram conjuntos de retalhos para tentar construir uma "concha" (cf. BACHELARD, 1993). Dentro dessa tentativa de construir "conchas" para cada uma das famílias, o fato de algumas serem parentes ameniza um pouco a convivência, a exposição e a ocorrência de conflitos. Assim, não se trata somente da quantidade de pessoas que dividem uma sala, mas sim quem são essas pessoas que estão dividindo. Conforme relata um dos chefes-de-família abrigados com a esposa, os três filhos e as três noras:

[Os lençóis foram colocados para separar os espaços] Que nem lá tinha cada um a sua casa, o seu quarto. [E pergunta para a nora]. 'Quantos quartos era na casa que vocês tinham lá?'. E responde a nora: 'Tinha três [quartos] e mais a sala, o banheiro e uma cozinha grande'. [E completa:] e tinha uma área grande na frente para fazer festas, essas coisas, né?Agora tá tudo aí ó[e apontando para a divisão feita no interior da sala das três famílias de seus filhos, com os quais, junto de sua esposa e seu filho solteiro, está convivendo]. A casa deles [dos filhos casados] agora é que nem aquela lá, aquele quadradinho lá [apontando para a divisão feita por lençóis], agora a outra [casa do outro filho casado] é aqui, tem uma aqui, a minha é ali [apontando para a divisão de espaços no interior da sala do abrigo] (Dezembro de 2008). 
Dentro desse território mínimo, as famílias tentavam recompor aspectos da realidade vivida na casa destruída, nos seus espaços de intimidade e nos objetos que permitiam compor parte de si, nos cuidados com o corpo, com o rosto, no olhar para si e no como se representar para o outro, na manipulação de sinais, cicatrizes, olheiras, os cuidados com a vaidade, com a saúde e autoestima, porque, num desastre, "não basta salvar corpos e não se preocupar com a reconstrução da alma", argumentava uma das entrevistadas. Assim, a tentativa de reterritorialização do mundo privado na escola-abrigo era permeada pelo modo como os agentes buscam "ser resilientes", reconstruir-se, mesmo que de forma precária e provisória.

Além das perdas materiais e imateriais já sofridas na emergência, a convivência num território forjado vai se constituindo num sofrimento social que é naturalizado, deixando a resiliência a cargo do próprio indivíduo. O controle dos corpos é feito pela coletivização e pela publicização, ao não permitirem a exibição do sofrimento e prescreverem os comportamentos ali aceitos, isto é, a dimensão positiva do poder (cf. FOUCAULT, 1984). Não se pode chorar em público; não se pode retirar em silêncio porque isso pode significar alguma patologia mental; deve-se participar de ocasiões de encontro coletivo no abrigo como, por exemplo, ceias de Natal; deve-se agradecer sempre a ajuda dos voluntários e não entrar em conflitos com eles; não se pode reclamar da comida. Não se pode pensar no mundo privado da família, porque isso não é visto como direito, mas como regalia. Assim, as rotinas do abrigo passam a ser criadas para desfazer os laços que construíam a realidade da família, como a mãe que cozinhava para seu filho, como a família que se reunia sozinha à mesa, como a esposa e o marido que tinham a privacidade do seu quarto de outrora: "No início havia sala com 19 pessoas. Hoje está menos. Não temos mais marido e mulher, é tudo irmão; não há privacidade”, relata abrigada no colégio Marcos Konder.

No abrigo capela Cristo Rei, também em Ilhota/SC, um salão paroquial em área rural foi utilizado para instalar as famílias, mas não havia separação em salas. Havia duas áreas: uma para "famílias" e outra para "homens solteiros". Uma das assistentes sociais de Ilhota havia relatado que diante da "improvisação" com que selecionaram e organizaram os abrigos, uma das principais preocupações se referia à forma com que as famílias estavam nos abrigos. Como verificado in loco, muitas famílias estavam dormindo num salão coberto, sem quaisquer divisórias que pudessem definir um território mínimo para cada família, isto é, todos ali eram iguais, uma "massa" que não permitia definir quem era quem, quem compunha tal família, onde era o limite de espaço físico de cada uma, não havia existência de qualquer fronteira visual como, por exemplo, uma parede feita de lençol. As condições para tentar ser resiliente variavam de abrigo para abrigo, isto é, não dependiam exclusivamente das características individuais dos "desabrigados".

Não raro, abrigos temporários também são locais de tentativas de suicídio, a antítese do "ser resiliente". No abrigo do colégio Marcos Konder, o coordenador do abrigo relatou que houve um caso de tentativa de suicídio, de uma moça grávida que já sofria de depressão antes de perder a casa e que, ao arcar com mais esse sofrimento e com a vida coletiva no abrigo, acabou ingerindo um excesso de comprimidos. No entanto, também havia outros riscos, como os riscos não só de suicídio, mas de transtorno do estresse pós-traumático. Alguns dos abrigados 
presenciaram parentes e vizinhos à beira da morte, tentando resgatá-los, salvá-los, e só estavam conseguindo ficar no abrigo à base de calmantes:

eu e meu marido não morremos por sorte. Tiramos a minha sogra com vida,
só que [começa a chorar]...não deu. (...) Nós vimos a morte dela e não
pudemos fazer nada. (...) A vida da minha sogra eu não consigo [mais]. Mas
eu quero tentar reconstruir a vida com meu marido. Eu não sei como ele tá
agüentando. Tenho medo que uma hora ele desabe. Eu só to conseguindo
ficar aqui [abrigo] à base de calmante. Ninguém mais agüenta (Dona
Onélia, abrigada no colégio Marcos Konder, dezembro de 2008; grifo
nosso).

A outra grande perda de Dona Onélia foi a de sua vizinha, a quem ela viu crescer e que vivia em sua casa. Dona Onélia estava num processo de luto pela perda de familiares, mas também pela morte da vizinha, a qual ficou agonizando à espera de resgate por mais de dez horas. Ela menciona os últimos momentos com a vizinha, o auxílio que ela lhe deu para ajudar a recolher as coisas para não pegar enchente, mas que de nada adiantou "porque tudo acabou-se no fundo do lodo":

fiquei bem angustiada (pausa)...Meu Deus, quem não fica, né?Perdi a minha vizinha tão querida... conhecia ela desde quando ela nasceu. Ela tinha vinte e sete anos. Era bem querida ela, bem querida com a gente. (pausa). Mas no fim morre todos nós, né? (Grande pausa). Ela ia de vez em quando lá em casa. Até sábado, quando começou a chover muito, ela foi lá em casa, ajudou a minha filha a recolher as coisas de baixo e colocar para cima [para não molhar]. Mas não adiantou de nada porque (pausa) acabouse tudo no fundo do lodo. (O, abrigada no salão paroquial Capela Cristo Rei, dezembro de 2008).

Segundo relataram os abrigados, as crianças também estavam sofrendo com a vivência no abrigo, perguntando aos pais "quando iam voltar pro [Morro do] Baú". Outras, porém não queriam voltar mais para o Baú diante do que aconteceu lá. Logo depois da organização dos abrigos, grupos de voluntários costumavam realizar atividades recreativas junto às crianças. Porém, com o passar da comoção social em relação ao ocorrido, essas atividades diminuíram enquanto a convivência no abrigo continuava sendo cada vez mais conflituosa. As condições para "ser resiliente" eram dinâmicas.

Segundo a vice-coordenadora do abrigo Marcos Konder, a maioria dos pais não queria realizar a ceia de Natal no abrigo, mas diante da situação dos seus filhos que viviam muito calados, resolveram organizar algo. Foi organizada uma árvore de natal - decorada com os presentes doados - no local onde se costumava fazer as refeições. Na ceia de Natal, algumas famílias abrigadas permaneceram durante o maior tempo da Ceia, enquanto outras jantaram e se retiraram para seus quartos. Algumas das famílias receberam visitas de parentes e amigos. Entre um desses havia um violeiro que cantava para algumas crianças que se reuniam à sua volta. Tempos depois, um grupo de pessoas abrigadas e visitas, acompanhados de seus violões, começaram a cantar músicas religiosas. Nessas ocasiões, a desterritorialização da casa é vivenciada novamente, principalmente quando esta incorporou uma trajetória de natais vividos, isto é, quando a casa era o local tradicional de reunião da família na época do Natal, e muitos organizavam os preparativos, selecionavam o cardápio, 
faziam a comida caipira para a "parentagem". Como relatou um dos abrigados no colégio Marcos Konder:

\begin{abstract}
porque fim de ano sempre vem a parentagem, é tio..é coisa que tem lá para Ibirama [cidade em Santa Catarina], tem sobrinhos que estão viajando [...] minha família toda são cinco filhos homens, só tem um solteiro, e tem os cunhados e tudo, então fim de ano eles vinham ali, visitar. Eles gostavam de chegar lá porque ali é a batata doce, o aipim - que alguns chamam "mandioca" e nós chama de "aipim" -, a galinha caipira era a preferência deles. Não precisava se incomodar com nada. la lá [no galinheiro] pegava uma ou duas galinhas-caipira fazia na panela, já pegava um aipim lá e já fazia, fazia aquela polenta no estilo italiano que fica uma hora mexendo...Agora nós temos que depender dos outros (olhos lacrimejados)" (A., abrigado no colégio Marcos Konder, dezembro de 2008).
\end{abstract}

Para além da resiliência no pós-emergência, como analisado no caso dos abrigos temporários, é importante discutir, ainda que brevemente, sobre as categorias casa e família/grupo doméstico no contexto das moradias provisórias (alugadas via auxílio-moradia) e/ou novas moradias (conjuntos habitacionais da reconstrução). Nesse âmbito de análise é possível transitar da dimensão microsociológica das estratégias de resiliência - elemento imprescindível da dimensão do capital humano e sua importância para qualquer modelo de desenvolvimento - para refletir sobre dinâmicas macrossociais como, por exemplo, o mercado de terras e de imóveis, as políticas habitacionais de reconstrução em desastres. Essas dinâmicas se relacionam aos modelos de desenvolvimento adotados e geram efeitos sobre as condições de resiliência. A fim de ilustrar essa problemática, discutir-se-ão alguns exemplos extraídos não só do desastre em Ilhota/SC, mas também em São Luiz do Paraitinga/SP.

Em Ilhota/SC, uma das principais preocupações das famílias abrigadas referiase à possibilidade de retorno ou não para suas propriedades e casas danificadas e/ou destruídas nas áreas rurais, conhecida como a região dos Baús. Essa definição também se relacionava a existência ou não de postos de trabalho na região, tendo em vista que muitos empreendimentos - plantações, serrarias - e estradas, que permitiam circulação de pessoas/mercadorias, foram danificados/destruídos. À essa situação se adicionava a pressão pública pela retomada das funções originais das infraestruturas públicas utilizadas como abrigo como, por exemplo, do retorno às aulas nas "escolas-abrigo". A solução temporária para desativação dos abrigos era o provimento de um auxílio-moradia para locação de imóveis. Entretanto, como verificado em outros desastres, é comum que a oferta de imóveis seja insuficiente para atender a demanda, que o valor do auxílio seja insuficiente para cobrir os custos, que os atingidos não tenham renda complementar para arcar com os custos de energia, água, alimentação, mobilidade - horizonte este por vezes mais fragilizado, em virtude da baixa oferta de postos de trabalho. Por vezes, outras variáveis sociais complexificam as soluções propostas: proprietários de imóveis decidem aumentar os preços de locação; ou se recusam a alugar em razão da incerteza quanto à regularidade das transferências do auxílio por parte do governo às famílias. Em São Luiz do Paraitinga, por exemplo, a inexistência de imóveis suficientes para locação fez com que quartos de pousadas fossem utilizados para abrigamento. 
No que se refere aos conjuntos habitacionais construídos para prover moradia às famílias atingidas, o universo das experiências registradas nos dois casos de estudo permite identificar o quão necessário é que modelos de desenvolvimento regional articulem os nexos entre moradia, trabalho e outros direitos sociais.

Em Ilhota/SC, a visita de campo em julho de 2011 foi realizada em uma comunidade da região dos Baús e também no novo conjunto habitacional, construído em uma área remota, dentro do perímetro urbano. No caso do novo conjunto habitacional havia problemas com as madeiras compradas para a construção das moradias, mas também com a inexistência de saneamento básico adequado, de posto de saúde, escola e de transporte público. Importante destacar outro fenômeno muito comum: essas soluções habitacionais prontas muitas vezes não consideram os modos de vida das famílias que irão residir nas moradias. Em São Luiz do Paraitinga, por exemplo, famílias que costumavam ter uma área para plantar dentro de suas propriedades foram sorteadas para residirem em apartamentos, em uma cidade em que não se tem o hábito de residir em um condomínio e negociar as regras coletivas de administrá-lo. Ademais, as regras do financiamento habitacional impedem que se façam modificações na fachada e na estrutura da moradia. A isso se adiciona a inexistência de postos de trabalho suficientes no município, o que faz com que muitos busquem ofertas de trabalho em cidades próximas, aumentando custos de mobilidade. O processo de reconstrução de São Luiz do Paraitinga se baseou no restabelecimento das condições socioeconômicas que precederam a inundação de 2010, sem refletir sobre a necessidade de diversificar e dinamizar o modelo de desenvolvimento econômico, reduzindo as desigualdades e vulnerabilidades existentes antes do desastre e intensificadas no decorrer deste como, por exemplo, o comprometimento das atividades turísticas (MARCHEZINI, SARTORI, GONÇALVES, 2017).

As tentativas de "ser resiliente" não se limitam à casa e à família/grupo doméstico, mas também se referem a outras dimensões da vida social, como o trabalho e a renda. Na seção seguinte, discutir-se-ão alguns elementos-chave desse tópico à luz do que os desastres, como laboratórios sociológicos, têm revelado.

\subsection{O trabalho e a caracterização no mundo social}

O trabalho e a renda são aspectos fundamentais para manutenção da família e da moradia, elementos importantes para a resiliência em desastres. Entretanto, o trabalho "vale não só por seu rendimento econômico, mas por seu rendimento moral” (SARTI, 2007, p.90). Para Sarti (2007, p.88), a identidade masculina, dentro e fora do âmbito familiar, "forja" um jeito de ser homem que se associa diretamente ao valor do trabalho, concebido muito mais do que o instrumento da sobrevivência material, mas como "condição de sua autonomia moral, ou seja, da afirmação positiva de si, que lhe permite dizer: eu sou". O trabalho se torna um atributo moral por meio do qual se afirma o valor da família frente ao caráter negativo imposto relacionalmente pelos agentes a partir da noção de ser pobre: há uma dimensão positiva que permite lutar simbolicamente na posição ocupada no espaço social, que advém do ser trabalhador (SARTI, 2007).

Em desastres, a identidade do ser trabalhador pode ser comprometida e/ou modificada ao longo do processo de resposta a desastres, reconstrução e 
recuperação. É comum que as pessoas atingidas relatem os trabalhos de resgate e de sobrevivência durante o momento da emergência, sejam nas inundações e/ou deslizamentos. Na região dos Baús, em Ilhota/SC, vários sobreviventes relataram os trabalhos comunitários de resgate de pessoas dos escombros, de recolhimento de vítimas fatais, de abertura de caminhos na mata para encontrarem rotas de fuga em direção a locais seguros, de vigilância para proteção dos bens materiais e de animais que permaneceram nas áreas atingidas (MENEZES, 2009). Em São Luiz do Paraitinga, ainda no cenário de emergência, empresas locais e praticantes de rafting do município utilizaram seus botes para realizarem inúmeros resgates madrugada adentro, até que as instituições oficiais de emergência chegassem ao local. Junto ao pessoal do rafting, inúmeros moradores abriram as portas de suas casas para acolher pessoas, preparar refeições etc. Alguns dividiram seus trabalhos no âmbito privado com as funções públicas exercidas, em razão da emergência. Sobre este último aspecto, cabe mencionar os trabalhos para resgatar documentos dos cartórios e do fórum, para resgatar imagens e outros itens das igrejas do município etc.

Ainda no período de emergência, emergem trabalhos para arrecadação de donativos em lugares para além dos cenários de destruição, assim como confluem para estes cenários voluntários de diversos tipos, na ânsia de executarem trabalho voluntário em prol do outro. Por vezes, os impactos dessa ajuda externa acabam gerando efeitos sobre a própria capacidade local em se recuperar. Um exemplo é a doação de alimentos e de roupas que confluem para áreas atingidas e que acabam reduzindo o dinamismo dos estabelecimentos comerciais locais em ofertar esse serviço, ainda que estes estejam danificados dias após a emergência. Outro impacto se refere ao trabalho logístico para fazer a triagem e destinação desses donativos. Em Ilhota/SC e São Luiz do Paraitinga/SP, a quantidade de doações acabou por comprometer a capacidade local de execução desses serviços, fazendo com que muitos donativos se tornassem resíduos, uma vez que não tinham utilidade alimentos com data de validade vencida, roupas e sapatos danificados etc.

No que concerne aos abrigos, a perda do espaço da casa também gera efeitos sobre os afazeres domésticos que se costumava realizar. Algumas idosas abrigadas no salão paroquial da Capela Cristo Rei reivindicavam uma participação nos afazeres domésticos realizados na cozinha do abrigo, porque isso significava uma forma de ajudar para se sentirem úteis e ocupar o tempo com trabalhos domésticos que se fazia em casa como lavar, cozinhar, limpar a casa etc.:

\footnotetext{
Dizem que eu não posso fazer nada porque eu não posso ficar em pé, né? Eu não posso ficar muito tempo em pé, né? [...] [Eu] queria [ajudar na cozinha], queria $\operatorname{sim}(. .$.$) [Queria] lavar. Lavar louça, secar....ajudar,$ né?Agora, no fogão não, né? No fogão eu já cozinhei o tempo todo [a vida toda] (risos). Lá em casa eu trabalhava, eu lavava roupa, eu cozinhava, limpava a casa... [...] Eu queria ajudar na cozinha, né? Lavar louça, só que para mim também não dá, né? Porque não posso ficar muito tempo em pé [tem úlcera], relata O., abrigada no Capela Cristo Rei.
}

Outros relataram a falta do trabalho no espaço rural, associado não somente à perda da casa em si, mas da propriedade como um todo, e do valor que a terra tinha. Conforme relata seu Rosalim (nome fictício): 
eu tinha minhas plantações de eucalipto. Tinha minha casa. Tinha equipamento para trabalhar na roça. O que eu precisava para trabalhar com maquinário eu tinha. Hoje eu não tenho nem um pedaço de serra mais, eu não acho mais lá. E o meu terreno lá, por causa da explosão, destruiu [...] Com 23 hectares de terra que hoje não dá para aproveitar nada, que não dá mais pra plantar um pé de nada. E era tudo terra boa que eu tinha lá para trabalhar. E o gás passava lá [na propriedade]. E não deram satisfação para gente desse gás. Porque antes da explosão do gás ali na nossa região não tinha nada [deslizamentos, avalanches de terras, enchentes]. E vão dizer que isso foi da enchente? Não, isso foi da explosão do gás" (R., abrigado no colégio Marcos Konder; dezembro de 2008; grifo nosso).

As estratégias de resiliência se associam ao voltar a trabalhar, na tentativa de recomposição das atividades de outrora. Por vezes, não se trata simplesmente de voltar a trabalhar, mas de recuperar a posição social na estrutura de classes. As relações de trabalho e a administração das empresas ficaram comprometidas durante o desastre, o que demonstra a necessidade de formular políticas públicas que estejam para além das doações e oferta de auxílio-moradia nos primeiros meses após a inundação. É clara a necessidade de pensar nos modelos de desenvolvimento regional em contextos de desastres. Em Ilhota, por exemplo, os impactos sobre as atividades empresariais na zona rural geraram efeitos sobre pessoas direta e indiretamente atingidas no desastre. Como afirma um empresário:

\begin{abstract}
eu sou empresário. Eu tenho uma serraria no Alto Baú e tô parado. Meus empregados estão parados. Não estão tendo pagamento. Eu não estou sendo indenizado. Não chegou ninguém para explicar o que aconteceu [em relação à possível explosão do gasoduto durante as chuvas]. [Explicar] se eles vão arrumar os clientes que eu estou perdendo. Eu quero uma resposta. [...] Como eu vou pagar minhas contas?E se eu me tornar inadimplente?[...] Noventa por cento da população do Alto Baú era patrão e empregado, a gente vivia daquilo ali, porque depender da Ilhota [cuja principal atividade econômica era indústria de moda íntima] não era fácil" ( $V$, abrigado no colégio Marcos Konder, dezembro de 2008).
\end{abstract}

Em São Luiz do Paraitinga, os estabelecimentos comerciais também foram prejudicados pela queda nas atividades turísticas do município, assim como pela ausência, logo nos primeiros meses após a inundação, de linhas de crédito com juros mais baixos, a fim de facilitar a recuperação das atividades econômicas. Esse processo é dinâmico, uma vez que a aprovação de novos projetos de reconstrução acarreta efeitos na economia local. Com o início da reconstrução da Igreja Matriz, por exemplo, moradores de São Luiz foram contratados para trabalharem nas obras e outras atividades de prestação de serviços foram demandadas, como a preparação de refeições por parte de restaurantes locais:

no desespero, no momento sensível ali, [pessoas] recorreram a empréstimos normais nos bancos. Depois se tentou empréstimo do governo, caixa de desenvolvimento do Estado de São Paulo, os juros eram juros lógico, eram juros alto pras pessoas naquele momento. E depois de um ano, um ano e meio chegou o Banco do Povo aqui em São Luiz do Paraitinga [...] Então ajudava, os juros eram bons, ai sim era possível fazer uma reconstrução. Então as pessoas acabaram adquirindo vários outros empréstimos por ai e estão tentando pagar [...] só no primeiro ano, pelo 


\begin{abstract}
fato da enchente, a gente deixou de ganhar uns setenta mil, né? Que é o começo da temporada, festival de marchinha, carnaval, que é forte nosso, que sustenta a gente praticamente no restante do ano, né? Diminuiu o fluxo de turista, então são dois meses, de dois a três meses de trabalhos pesado que segura o restante do ano, então a gente perdeu isso, e não só perdemos isso no primeiro ano de enchente [2010], com esse segundo ano [2011] que veio agora também, foi totalmente aquém do que a gente achava do que poderia ser [...]. Muita gente quebrou, que nem eu tava quase fechando as portas aqui, só não vou fechar as portas aqui, porque na última hora eu consegui fechar um contrato com a empresa que vai vir trabalhar agora aqui na igreja, que ela vai reconstruir a igreja, que vai ser em torno de oitenta a cem funcionários. Então, a partir de janeiro agora ela começa a trabalhar e começa um fluxo diário aqui de café da manhã, almoço e jantar, porque a gente estava assim, você está aqui e está vendo o movimento... (entrevista realizada em novembro de 2011).
\end{abstract}

Os modelos de desenvolvimento regional que almejam subsidiar as estratégias de resiliência a desastres precisam levar em conta essas dimensões humanas e sociais dos processos de reconstrução e recuperação em desastres. A Sociologia dos Desastres pode contribuir para a análise dessas estruturas sociais e das relações entre os agentes, com vistas a subsidiar políticas públicas que articulem essas dimensões.

\title{
4 Conclusões e recomendações
}

Os desastres, como laboratórios sociológicos, permitem analisar as dimensões sociais da resiliência a fim de compreender, em uma perspectiva micro e macrosociológica, os fatores que contribuem ou dificultam a adoação de estratégias para fazer frente a situações adversas. A compreensão destes fatores é fundamental para o planejamento de políticas públicas voltados ao desenvolvimento regional frente a desastres, que priorize a qualidade de vida em detrimento da reprodução de condições desigualdade e de vulnerabilidade que precedem os desastres.

A partir dos estudos de caso dos desastres de Ilhota/SC e São Luiz do Paraitinga/SP, este artigo compartilhou alguns resultados empíricos, identificando três aspectos fundamentais para compreensão do conceito de resiliência e das estratégias de desenvolvimento que dele podem derivar. Esses três elementos são: a família e/ou grupo doméstico, a casa e o trabalho. Por constituírem-se em fatores fundamentais para a caracterização dos agentes no mundo social, as políticas públicas de desenvolvimento regional precisam contemplar esses aspectos, articulando diferentes setores do conhecimento. Nesse sentido, é necessário que esforços no âmbito da psicologia das emergências e dos desastres - centrados, por exemplo, na resiliência da família/grupo doméstico - se façam acompanhar por políticas habitacionais articuladas ao desenvolvimento regional, envolvendo, por exemplo, setores assistencial, habitacional, planejamento regional. Em São Luiz do Paraitinga/SP, um esforço de articulação foi a criação do Centro de Reconstrução Sustentável de São Luiz do Paraitinga (Ceresta). Entretanto, embora a construção de novas moradias tenha ocorrido em um prazo relativamente curto (oito meses), essa estratégia não foi articulada a outras iniciativas de geração de emprego não limitadas ao período emergencial, ou seja, não restritas à execução de obras de reconstrução. Esses desafios revelados pelas pesquisas de campo indicam a necessidade de 
promover mais pesquisas e debates sobre o tema a fim de aumentar a capacidade nacional em lidar com o assunto.

\section{Contribuições dos autores}

VM e HAF contribuíram para a fundamentação teórico-conceitual e problematização, elaboração e redação do texto, seleção das referências bibliográficas e análise dos dados de pesquisas de campo. VM também para a pesquisa e coletas de dados em campo em Ilhota/SC e São Luiz do Paraitinga/SP, que foram financiadas com recursos da FAPESP (Processos 08/51947-0 e 09/54877-5). As opiniões, conclusões e recomendações expressas nesse material são dos autores e não necessariamente refletem as visões das instituições de financiamento e às quais pertencem.

\section{Referências}

ACOSTA, V. G. El riesgo como construcción social y la construcción social de riesgos. Desacatos- Revista de Antropologia Social. Septiembre/diciembre, n. 19, p.11-24, 2005. Disponível em:< http://redalyc.uaemex.mx/pdf/139/13901902.pdf >. Acesso em: 30 maio. 2011

BACHELARD, G. A poética do espaço. São Paulo: Martins Fontes, 1993.

BLAIKIE, P.; CANNON, T.; DAVIS, I.; WISNER, B. At risk - natural hazards, people's vulnerability, and disasters. London and New York: Routledge/ Taylor \& Francis eLibrary, 2005.

BOURDIEU, P. O Poder Simbólico. Rio de Janeiro: Bertrand Brasil, 2004.

BRANDÃO, J.M.; MAHFOUD,M. ; GIANORDOLI-NASCIMENTO, I. F . A construção do conceito de resiliência em psicologia: discutindo as origens. Paidéia (USP. Ribeirao Preto. Impresso), v. 21, p. 263-271, 2011.

\section{ESCRITÓRIO DAS NAÇÕES UNIDAS PARA REDUÇÃO DE RISCOS DE DESASTRES (UNISDR). Como Construir Cidades Mais Resilientes - Um Guia para Gestores Públicos Locais. Genebra, Novembro, 2012.}

FOUCAULT, P.M. Microfísica do Poder. Rio de Janeiro: Graal, 1984.

FREHSE, F. et al. O estranho do sonho: entre o imediato e o possível. In: MARTINS, J.de S. (Org.). (Des)figurações: a vida cotidiana no imaginário onírico da metrópole. São Paulo: Ed.Hucitec, 1996, p.73-100.

GONÇALVES, C. Regiões, cidades e comunidades resilientes: novos princípios de desenvolvimento. Revista Brasileira de Gestão Urbana. v. 9, pp.371-385, 2017. 
GOVERNO DO ESTADO DE SANTA CATARINA. Centro de Informática e Automação do Estado de Santa Catarina. Mapa interativo de Santa Catarina. 2009. Disponível em:http://www.mapainterativo.ciasc.gov.br/sc.phtml. Acesso em: 05 fev. 2009.

GRESSLER, S.C. Habitação e design. Um estudo comparativo entre residências em Dourados, Mato Grosso do Sul, Brasil, e Columbia, Missouri, E.U.A. Revista de Pesquisa em Arquitetura e Urbanismo. n5, p.63- 79, 2007.

HIGUCHI, M.I.G. A sociabilidade da estrutura espacial da casa: processo histórico de diferenciação social por meio e através da habitação. Revista de Ciências Humanas, n.33, p.49-70, 2003.

MANYENA, S. B. The concept of resilience revisited. Disasters, 2006, 30(4): 433-450.

MARCHEZINI, V. Dos desastres da natureza a natureza dos desastres. In: VALENCIO, N.; SIENA, M.; MARCHEZINI, V.; GONÇALVES, J. C. (Orgs.). Sociologia dos Desastres: construção, interfaces e perspectivas no Brasil. São Carlos: Rima Editora, 2009, p. 48-57.

MARCHEZINI, V. La producción silenciada de los "desastres naturales" en catástrofes sociales. Revista Mexicana de Sociología, v.76, n.2, p.253-285, $2014 a$.

MARCHEZINI, V. Campos de desabrigados: a continuidade do desastre. São Carlos: Rima Editora, 2014b.

MARCHEZINI, V. Processos de recuperação em desastres: discurso e práticas. São Carlos: Rima Editora, 2014C.

MARCHEZINI, V. As ciências sociais nos desastres: um campo de pesquisa em construção. Revista Brasileira de Informação Bibliográfica em Ciências Sociais BIB, v. 83, p. 43-72, 2018.

MARCHEZINI, V.; SARTORI, J.; GONCALVES, J. C. Desenvolvimento, Desastres e Reconstrução: o caso de São Luiz do Paraitinga/SP, Brasil. Revista Brasileira de Gestão e Desenvolvimento Regional, v.13, p.202 - 226, 2017.

MARTINS, J. de S. A peleja da vida cotidiana em nosso imaginário onírico. In (Des)figurações: a vida cotidiana no imaginário onírico da metrópole. São Paulo: Ed.Hucitec, 1996, p.15-72.

. Sociologia da Fotografia e da Imagem. São Paulo: Contexto, 2008.

MASKREY, A. (Eds.). Los desastres no son naturales. Cidade do Panamá: Red de Estudios Sociales en Prevención de Desastres en América Latina, 1993.

MENEZES, J. G. R. de. A tragédia do Morro do Baú. Blumenau: Nova Letra, 2009. 
ONU-DOCUMENTOS DA HABITAT III. Resiliência Urbana. Nações Unidas, Nova York, Maio, 2015.

O'KEEFE, P.; WESTGATE K.; WISNER, B. Taking the 'Naturalness' Out of 'Natural' Disasters. Nature 260, n.5552, p. 566-567, 1976.

OLIVER-SMITH, A. Reconstrucción después del desastre: una visión general de secuelas y problemas. In: LAVELL, A. (Org.). Al Norte del Rio Grande. Cidade do Panamá: Red de Estudios Sociales en Prevención de Desastres en América Latina, 1994, p.25-40.

PREFEITURA MUNICIPAL DE SÃO LUIZ DO PARAITINGA. Formulário de Avaliação de Danos. 01 jan. 2010 a. $2010 b$. . Como tudo aconteceu. Jornal da Reconstrução. $1^{\mathrm{a}}$ quinzena de março.

QUEIROZ, M.I.P. Variações sobre a técnica de gravador no registro da informação viva. São Paulo: T.A. Queiroz, 1991.

REBOTIER, J.; PELÁZEZ, J.L.; PIGEON, P. Las paradojas de la resiliência: miradas cruzadas entre Colombia y Francia. Territórios, 28, pp. 127-145, Bogotá, 2013.

SANTOS, J.R.C.C. A cultura como protagonista do processo de reconstrução da cidade de São Luiz do Paraitinga/SP. Tese, Universidade de São Paulo, São Paulo, 2015.

SANTOS, D. M. S. Os sentidos da patrimonialização no processo de reconstrução de São Luiz do Paraitinga. Dissertação, Universidade de Taubaté, Taubaté, 2016.

SOUZA, M. T. S. Resiliência e desastres naturais. Ciência e Cultura, v. 63, p. 4-5, 2011.

SARTI, C. A. A Família Como Espelho: um estudo sobre a moral dos pobres. São Paulo: Cortez, 2007.

SARTORI, J. Como esquecer? Memórias de um desastre vivenciado. Dissertação, Universidade de São Paulo, São Carlos, 2014.

SIENA, M. A Atenção Social nos Desastres: uma análise sociológica das diversas concepções de atendimento aos grupos sociais afetados. Tese, Universidade Federal de São Carlos, São Carlos, 2012.

TIDAFI, M. R. V. Estar aqui sendo de lá: sentidos de urbano e de rural na produção da cidade e na mobilidade sócio-espacial em Teresina-PI. In: $30^{\circ}$ Encontro Anual da ANPOCS, 2006, Caxambu. Anais... Caxambu: ANPOCS, 2006. 31p. 
VALENCIO, N.F.L.S. Para além do ‘dia do desastre’. Curitiba: Editora Appris, 2012.

VALENCIO, N.F.L.S. et al. A produção social do desastre: dimensões técnicas e político-institucionais da vulnerabilidade das cidades brasileiras frente às chuvas. Revista Teoria e Pesquisa, v 44-45, p. 67-115, 2004.

VALENCIO, N.; SIENA, M.; MARCHEZINI, V. Abandonados nos desastres: uma análise sociológica de dimensões objetivas e simbólicas de afetação de grupos sociais desabrigados e desalojados / Norma Valencio. - Brasília: Conselho Federal de Psicologia, 2011.160 p.

WISNER, B., GAILLARD, JC, \& KELMAN, I. Framing disaster: Theories and stories seeking to understand hazards, vulnerability and risk. In: WISNER, B.; GAILLARD, J.C.; KELMAN, I. (Orgs.). The Routledge handbook of hazards and disaster risk reduction. London: Routledge, 2012, p.18-34.

Victor Marchezini. Doutor e mestre em Sociologia pelo Programa de PósGraduação em Sociologia, da Universidade Federal de São Carlos (UFSCar). Bacharel em Ciências Sociais pela UFSCar e Licenciado em Ciências Sociais pela Universidade Estadual Paulista - UNESP/FCL- Araraquara. Especialista em Direitos Humanos, Gestão Global de Riscos e Políticas Públicas de Prevenção de Desastres pela Fundação Henry Dunant - América Latina. Especialista em educação a distância pela Faculdade Anhanguera-Uniderp. Foi pesquisador do Núcleo de Estudos e Pesquisas Sociais em Desastres (NEPED/UFSCar) no período de 2004 a 2011. Tem experiência na área de Sociologia, com ênfase em Sociologia dos Desastres. Foi analista operacional (2012-2014) no Centro Nacional de Monitoramento e Alerta de Desastres Naturais (CEMADEN), do Ministério de Ciência, Tecnologia e Inovação. Atualmente é pesquisador associado no Cemaden. É integrante de dois grupos de pesquisa certificados junto ao CNPq: o Grupo de Pesquisa "Estudos de Mudanças de clima, detecção, avaliação de impactos e vulnerabilidade" (coordenado pelo INPE) e do "Grupo Pesquisador em Educação Ambiental, Comunicação e Arte - GPEA" (coordenado pela UFMT). A partir de outubro de 2018, passou a ser docente colaborador no Programa de PósGraduação em Ciências do Sistema Terrestre, no Instituto Nacional de Pesquisas Espaciais (INPE). É membro do conselho do comitê de pesquisa em Sociologia dos Desastres (RC 39), da Associação Internacional de Sociologia (ISA). victor.marchezini@gmail.com

Henrique Almeida Forini. Graduando em Ciências Sociais pela Universidade Federal de São Carlos com ênfase em Sociologia. É membro do grupo de pesquisa "Ideias e Instituições para o Desenvolvimento e a Democracia" (CNPq/UFSCar). Desenvolveu pesquisa de iniciação científica como bolsista PIBIC analisando o impacto das Ações Afirmativas na composição do conselho universitário da UFSCar. Atualmente é bolsista pelo CEMADEN (CNPq) e realiza pesquisa sobre "cidades resilientes" na área de sociologia dos desastres. Trabalhou também como pesquisador do Observatório Nacional de Política de Assistência Estudantil durante o ano de 2016. forini.henrique@gmail.com 
Como citar: MARCHEZINI, Victor; FORINI, Henrique Almeida. Dimensões sociais da resiliência a desastres. Redes, Santa Cruz do Sul, v. 24, n. 2, p. 9-28, maio 2019. ISSN 1982-6745. Disponível em: https://doi.org/10.17058/redes.v24i2.13000. 